ISSN 0853-8697

\title{
PENERAPAN METODE ATTRIBUTE EXTRACTION PADA PROSES PERANCANGAN BERBASIS KOMPUTER DAN PENYUSUNAN BILL OF MATERIALS PRODUCT Kasus Perancangan Desain Tempat Tidur Pasien Rumah Sakit
}

\author{
Agus M ansur, Evin K. Prasetia Adi \\ J urusan Teknik Industri, Fakultas T eknologi Industri, U niversitas Islam Indonesia \\ Jl. Kaliurang Km. 14 Y ogyakarta 55501 \\ Telp. (0274) 89528, Faks. (0274) 895007ext. 148 \\ E-mail: gus_mansur@yahoo.com
}

\begin{abstract}
During the design process, there still many industries use conventional system which can not completely accommodate the need of information. That's why we need a system that can accommodate the necessity of designer and also end product user.

Until now, what computer does in design process is only use as drawing tools. While the other vital functions like attribute geometric data and attribute non-geometric data is not use. This researcht is discussed about the design of patient's bed in the hospital by using CAD, we hope that by using Attribute Extraction M ethod in CAD, we can get ergonomic design, Bill of $M$ aterials $P$ oduct, Component of D raw Template, Supplier of the Basis Geometric Data and also to design animation's product. So that, the experiment's result can easier the machine process design and also the management supply of materials need.
\end{abstract}

Keywords: product design, attribute extraction, bill of materials.

\section{PENDAHULUAN}

\subsection{Latar Belakang}

Mulai bergesernya orientasi desain produk dari orientasi kemudahan produksi ke arah orientasi pada kebutuhan konsumen merupakan tantangan tersendiri bagi para perancang produk dan pengambil keputusan untuk membuat produk yang berorientasi pada keinginan konsumen [6]. Banyaknya konsumen yang mulai kritis dalam memilih dan menentukan produk, dan dengan dilatarbelakangi krisis ekonomi seperti ini menjadikan konsumen lebih selektif dalam memilih produk yang diinginkan. Hal ini menuntut perusahaan untuk semakin meningkatkan pelayanan terhadap konsumen, dengan harapan konsumen tidak berpindah keperusahaan lain.

Penelitian ini membahas tentang bagaimana merancang desain tempat tidur pasien rumah sakit yang ergonomic berdasarkan data anthropometri manusia, sekaligus dapat memberikan laporan mengenai susunan Bill of $\mathrm{M}$ aterials produk yang dibuat.

Dengan menggunakan CAD sebagai salah satu teknik di bidang perancangan yang memfokuskan pada perilaku perancangan berbasis computer, sehingga diharapkan desain yang dibuat mampu merepresentasikan secara jelas bentuk produk yang diinginkan [9]. 


\subsection{Batasan Masalah}

Beberapa batasan dibuat untuk memfokuskan penelitian:

1. Produk yang akan diteliti adalah tempat tidur pasien mekanis dengan penggerak sistem elektrik untuk konsumen rumah sakit kelas VIP.

2. Komponen yang didesain hanya mencakup komponen utama penyusun produk tersebut.

3. Penelitian hanya mencakup proses desain saja dan tidak membahas rangkaian sistem kelistrikan yang dipasang pada objek penelitian.

4. Aktivitas ekstraksi atribut sebagai penyusun Bill of $M$ aterials produk hanya bersifat sebagai penyedia basis data, dan bukan sebagai aplikasi basis data.

\subsection{Tujuan Penelitian}

Penelitian ini bertujuan untuk:

1. Menerapkan dan memaksimalkan penggunaan CAD (Computer-A ided Design) pada pembuatan desain produk sehingga dapat mengakomodasi produsen dalam mengefektifkan proses perancangan.

2. Mendapatkan hasil desain yang mudah untuk dimodifikasi, baik data geometris maupun non-geometrisnya.

3. Menemukan cara yang lebih baik pada proses perancangan produk.

\section{LANDASAN TEORI}

\subsection{Anthropometri}

Antropometri adalah suatu studi atau pengetahuan yang menyangkut pengukuran tubuh manusia khususnya yang berhubungan dengan dimensi fisik manusia. Hal ini didasari oleh keragaman bentuk badan, ukuran tubuh, berat badan dan perbedaan fisik lain yang ada pada fisik manusia. Secara luas antropometri digunakan sebagai pertimbangan-pertimbangan ergonomis dalam proses perancangan produk maupun sistem kerja yang memerlukan interaksi manusia [10].

Dalam sistem pengukuran, antropometri terbagi menjadi 2 bagian yaitu antropometri statis dan antropometri dinamis. Antropometri statis merupakan cara pengukuran dimensi tubuh manusia yang dilakukan pada saat posisi diam. Dimensi ini diambil secara linier dan tepat diletakkan pada permukaan tubuh. Agar hasil pengukuran tersebut representatif, maka pengukuran harus dilakukan dengan metode tertentu terhadap beberapa individu [7].

\subsection{Computer-Aided Design Systems}

CAD (Computer-Aided Design) merupakan suatu konsep perilaku desain berbantuan komputer dengan alat bantu berupa perangkat lunak yang memiliki banyak keunggulan. Keunggulan tersebut antara lain cepat, akurat, estetis dan efektif, sehingga sangatlah tepat jika diterapkan oleh produsen untuk memenuhi keinginan para konsumennya [8]. Tidak mengherankan jika penggunaan sistem CAD diterapkan pada proses perancangan, maka total waktu produksi akan dapat direduksi.

Keuntungan menggunakan CAD dalam perancangan produk adalah [3]: 
1. Mutu Produk. CAD memungkinkan bagi desainer dalam alternatif pengembangan dan mengetahui masalah yang terdapat dalam desain sebelumnya.

2. Waktu perancangan terpendek. CAD benar-benar mempengaruhi pada biaya maupun waktu pelemparan hasil pengembangan ke pasar.

3. Pengurangan biaya proses produksi. Perubahan rancangan secara mudah sudah disediakan, group technology selanjutnya membantu dengan mengelompokkan komponen untuk proses produksinya.

4. M anajemen data base. Biasanya data base berarti informasi yang menjadikan akurat. Kecepatan transfer dan perbaikan dokumen menjadi lebih mudah.

5. M eningkatkan kemampuan. Kemampuan untuk melihat desain dari berbagai macam sudut pandang kelihatan jelas dalam model 3-D menjadikan desain lebih realistis dalam hal ruangan dan pengamatan perencanaan penting lainnya. Juga hubungan dan kombinasi antar desain menjadikan mungkin ketika kita menginginkan.

Karena itu, sistem CAD (Computer-Aided D esign) sesungguhnya merupakan penggabungan antara kemampuan seorang desainer terbaik dengan komputer untuk menghasilkan desain terbaik dan proses manufaktur dari produk [1].

\section{METODOLOGI PENELITIAN}

\subsection{Diagram Alir Penelitian}

Gambar 1

Langkah-langkah yang dilakukan dalam penelitian ini ditunjukkan pada 


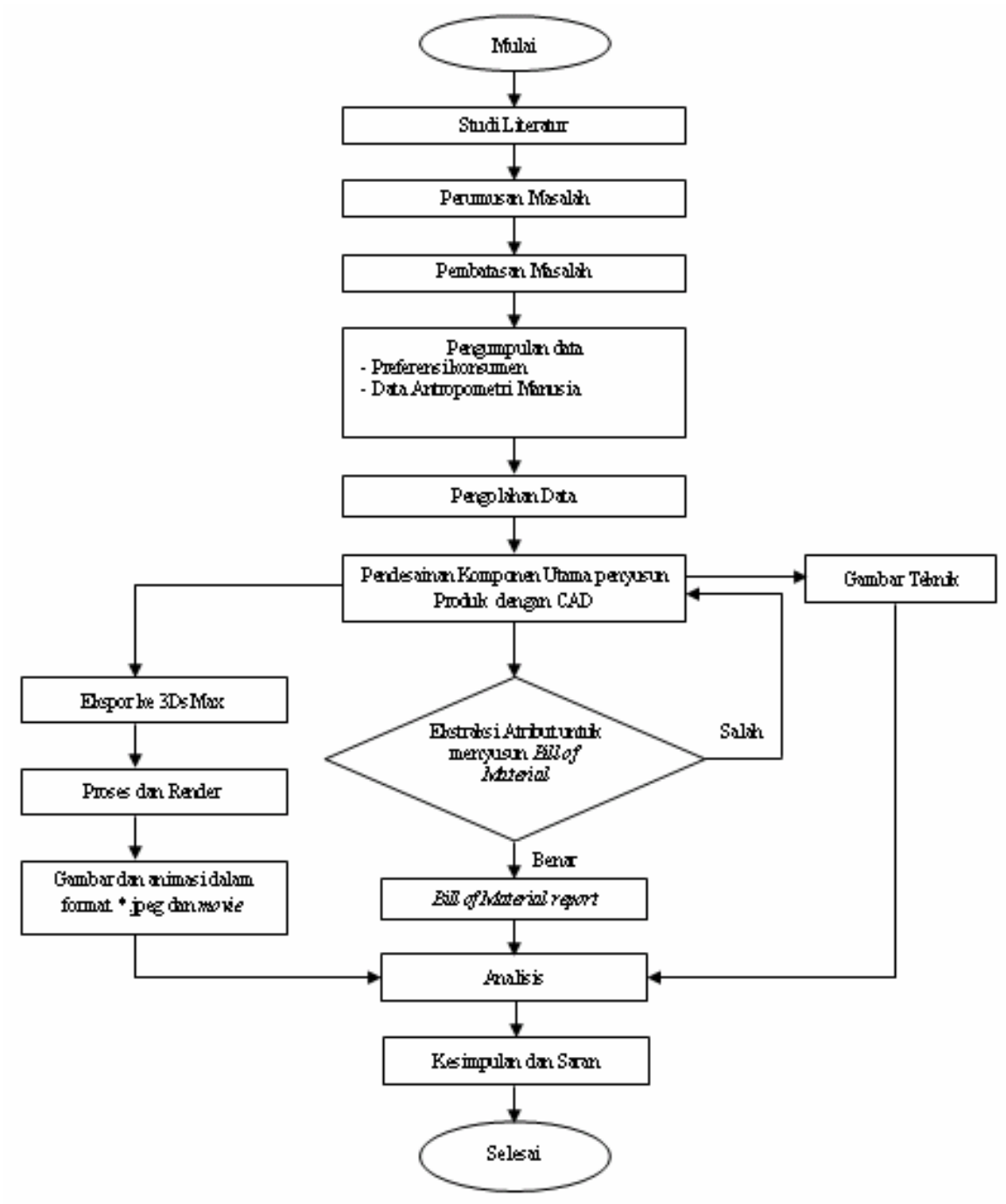

Gambar 1. Diagram alir penelitian

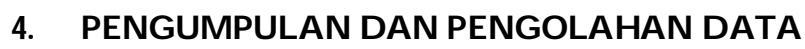

4.1 Pengumpulan Data

4.1.1 Preferensi Konsumen

Dari survey yang dilakukan didapatkan atribut dalam desain produk yang diinginkan konsumen (lihat Tabel 1), atribut-atribut ini kemudian dijadikan sebagai salah satu acuan dalam pendesainan produk. 
Tabel 1. Preferensi konsumen

\begin{tabular}{|c|l|}
\hline $\mathrm{N} 0$ & \multicolumn{1}{|c|}{ D eskripsi } \\
\hline 1 & $\begin{array}{l}\text { Konsumen menginginkan rancangan tempat tidur pasien yang dapat diatur posisi } \\
\text { tinggi-rendahnya agar dapat di sesuaikan pada saat akan digunakan. }\end{array}$ \\
\hline 2 & $\begin{array}{l}\text { Konsumen menginginkan bahwa tempat tidur tersebut memiliki alas yang dapat } \\
\text { disesuaikan pada saat digunakan. (terdapat 4 bagian utama pada alas) }\end{array}$ \\
\hline 3 & $\begin{array}{l}\text { Konsumen menginginkan agar tempat tidur tersebut dilengkapi pembatas kanan- } \\
\text { kiri agar faktor keamanan pada saat penggunaan dapat dirasakan. }\end{array}$ \\
\hline 4 & $\begin{array}{l}\text { Pengguna selain pasien (perawat) menginginkan tempat tidur tersebut memiliki } \\
\text { roda agar dapat dipindah-pindahkan tanpa harus memindahkan pasien ke ruangan } \\
\text { lainnya. }\end{array}$ \\
\hline 5 & $\begin{array}{l}\text { Pengguna selain pasien (perawat) menginginkan agar panel pembatas kepala dan } \\
\text { kaki dapat dilepas sehingga memudahkan pada saat melakukan perawatan pada } \\
\text { pasien. }\end{array}$ \\
\hline 6 & $\begin{array}{l}\text { Konsumen dalam hal ini pasien maupun perawat menginginkan sistem penggerak } \\
\text { tempat tidur tersebut bersifat elektris agar lebi h mudah dalam pengoperasiannya. }\end{array}$ \\
\hline 7 & $\begin{array}{l}\text { Konsumen menginginkan bahwa material penyusun yang digunakan terbuat dari } \\
\text { bahan-bahan yang awet dan memiliki nilai estetis yang bagus secara visual. }\end{array}$ \\
\hline 8 & $\begin{array}{l}\text { Konsumen menginginkan agar alas yang dipakai terbuat dari bahan yang dapat } \\
\text { menyerap panas. }\end{array}$ \\
\hline 9 & $\begin{array}{l}\text { Konsumen menginginkan adanya pengaman pada roda, sehingga pada saat tempat } \\
\text { tidur dalam kondisi diam tidak bergeser. }\end{array}$ \\
\hline 10 & $\begin{array}{l}\text { Konsumen menginginkan adanya tiang infus yang dapat dipasang di tempat tidur } \\
\text { tersebut atau dilepas dari tempat tidur. }\end{array}$ \\
\hline
\end{tabular}

Dari data preferensi konsumen tersebut, maka komponen-komponen utama yang perlu untuk dirancang adalah:

1. Alas tempat tidur (terdiri dari: back raise, knee raise)

2. Ketinggian alas tempat tidur (H i-Lo bed position)

3. Infuse Stand (tempat untuk meletakkan infus)

4. Kondisi head and foot panel

5. Kondisi safety side guard

6. Kondisi roda (castor)

7. Kondisi poros angkat

8. Mekanisme sistem penggerak.

\subsubsection{Data Anthropometri Acuan Perancangan}

Setelah mendapatkan data preferensi konsumen, langkah berikutnya adalah melakukan pengukuran terhadap Anthropometri manusia (calon pengguna potensial). Data anthropometri yang digunakan ditunjukkan pada Tabel 2. 
Tabel 2. Data Anthropometri (ukuran dalam cm)

\begin{tabular}{|c|c|c|c|c|c|c|}
\hline & $\mathrm{tdt}$ & $\mathrm{Lb}$ & $\mathrm{plb}$ & tpo & tsb & tbt \\
\hline 1 & 78 & 37 & 22 & 32 & 95 & 155 \\
\hline 2 & 80 & 37 & 23 & 38 & 96 & 155 \\
\hline 3 & 80 & 37 & 23 & 39 & 96 & 155 \\
\hline 4 & 80 & 46 & 23 & 39 & 97 & 155 \\
\hline 5 & 80.5 & 40 & 23 & 40 & 97.5 & 157 \\
\hline 6 & 82 & 46 & 24 & 40 & 98 & 157.5 \\
\hline 7 & 82 & 38 & 24 & 41 & 98 & 158 \\
\hline 8 & 82 & 35 & 24 & 41 & 98 & 158 \\
\hline 9 & 83 & 36 & 24 & 41 & 98 & 159 \\
\hline 10 & 83 & 36 & 24 & 42 & 100 & 159 \\
\hline 11 & 83 & 39 & 24 & 43 & 100 & 161 \\
\hline 12 & 84 & 36 & 24.3 & 43.5 & 100 & 162 \\
\hline 13 & 84 & 40 & 25 & 44 & 100 & 163 \\
\hline 14 & 85 & 34 & 25 & 45.5 & 100.5 & 164 \\
\hline 15 & 85 & 40 & 25 & 46.3 & 102 & 165 \\
\hline 16 & 85 & 40 & 25.5 & 47 & 104 & 166 \\
\hline 17 & 86 & 38 & 25.5 & 47 & 106 & 166 \\
\hline 18 & 86 & 50 & 26 & 47 & 106 & 168 \\
\hline 19 & 86 & 49 & 26 & 41.5 & 106.5 & 169 \\
\hline 20 & 86 & 38 & 26 & 42 & 106.5 & 169 \\
\hline 21 & 86.5 & 38 & 26.5 & 39 & 107.5 & 170 \\
\hline 22 & 87 & 42 & 26.5 & 51 & 107.5 & 170 \\
\hline 23 & 89 & 46 & 27 & 55 & 108 & 170.5 \\
\hline 24 & 90 & 40 & 26 & 43.5 & 103 & 171 \\
\hline 25 & 90 & 38 & 27 & 45 & 108 & 171 \\
\hline 26 & 90 & 45 & 28 & 48 & 110 & 171 \\
\hline 27 & 91 & 41 & 28 & 50 & 110 & 172 \\
\hline 28 & 91 & 40 & 28 & 40.5 & 107 & 174 \\
\hline 29 & 92 & 36 & 29 & 44 & 110 & 175 \\
\hline 30 & 90 & 47 & 26 & 38 & 105 & 166 \\
\hline
\end{tabular}

Selanjutnya data diuji tingkat keseragaman dan kecukupannya, hal ini dilakukan untuk menghindari nilai bias yang ekstrim.

\subsection{Pengolahan Data}

4.2.1 Data Anthropometri Acuan Perancangan

Berdasarkan Table 3 dan 4, dapat dinyatakan data sudah seragam dan cukup reliable untuk dijadikan sebagai input perancangan. Selanjutnya dengan memasukkan nilai persentil yang sesuai dengan kebutuhan end-user didapatkan dimensi perancangan seperti yang diterangkan dalam Table 5 .

Tabel 3. Tes keseragaman data

\begin{tabular}{|c|c|c|c|c|c|}
\hline D ata & D ata M in. & D ata M ax. & BKA & BK B & K eterangan \\
\hline Tdt & 78 & 92 & 95.17804 & 75.28862 & Seragam \\
Lb & 37 & 50 & 59.34113 & 34.65887 & Seragam \\
Plb & 22 & 29 & 29.82664 & 20.72669 & Seragam \\
Tpo & 32 & 51 & 54.98517 & 31.26816 & Seragam \\
Tsb & 95 & 110 & 126.9376 & 75.32903 & Seragam \\
Tbt & 155 & 166 & 180.7994 & 148.0006 & Seragam \\
\hline
\end{tabular}

156 Mansur \& Adi - Penerapan M etode A ttributeExtraction pada Proses Per ancangan ... 
Tabel 4.Tes kecukupan data

\begin{tabular}{|c|c|c|c|}
\hline Data & $\mathrm{N}$ & $\mathrm{N}^{\prime}$ & Keterangan \\
\hline Tdt & 30 & 3.038 & Cukup \\
Lb & 30 & 19.344 & Cukup \\
Plb & 30 & 7.23 & Cukup \\
Tpo & 30 & 16.87 & Cukup \\
Tsb & 30 & 14.53 & Cukup \\
Tbt & 30 & 2.22 & Cukup \\
\hline
\end{tabular}

Tabe 5. Data dimensi acuan perancangan

\begin{tabular}{|c|l|c|c|c|}
\hline No. & \multicolumn{1}{|c|}{ Data geometris } & Persentil & Hasil dari & D imensi $(\mathbf{c m})$ \\
\hline 1 & $\begin{array}{l}\text { Tinggi tempat tidur posisi } \\
\text { tinggi }\end{array}$ & P5 & Tsb-Plb & $62.305 \approx 63$ \\
\hline 2 & $\begin{array}{l}\text { Tinggi tempat tidur posisi } \\
\text { rendah }\end{array}$ & P50 & Tpo & $43.127 \approx 43$ \\
\hline 3 & Alas bagian punggung & P99 & Tdt & $94.195 \approx 94$ \\
\hline 4 & $\begin{array}{l}\text { Tinggi lubang pegangan } \\
\text { panel posisi berdiri dari } \\
\text { lantai }\end{array}$ & P10 & Tsb & $88.331 \approx 88$ \\
\hline 5 & Tinggi tempat infuse & P5 & Tbt+Plb & $176.5 \approx 177$ \\
\hline 6 & Lebar matras & P99 & Lb+(0.5*Lb) & $87.182 \approx 87$ \\
\hline 7 & Panjang matras & P99 & Tbt & $179.178 \approx 180$ \\
\hline 8 & Jarak lubang pada panel & P1 & Lb & $35.878 \approx 36$ \\
\hline
\end{tabular}

\subsubsection{Tahap Perancangan Gambar}

Langkah-langkah berikut dilakukan pada tahap perancangan gambar:

1 Sketsa manual objek yang akan didesain pada komputer.

2. Sesuaikan data anthropometri dengan objek yang akan didesain.

3. Buat objek gambar pada AutoCAD dan terapkan prosedur Layer Properties $M$ anagement. Berikan nama Layer sesuai dengan kondisi komponen sebenarnya.

4. Hasil gambar siap untuk diproses.

\subsubsection{Tahap Pendefinisian Atribut}

Untuk memaksimalkan gambar yang sudah dibuat dengan urutan proses diatas, maka diperlukan adanya suatu manajemen gambar (lihat Gambar 2). Manajemen gambar ini berupa pemberian atribut yang berisi tentang informasiinformasi yang diperlukan untuk tiap-tiap komponen. Pemberian atribut dilakukan dengan perintah Attribute Definition/ATTDEF sehingga setiap komponen akan memiliki keterangan sesuai dengan yang diisikan oleh user. 


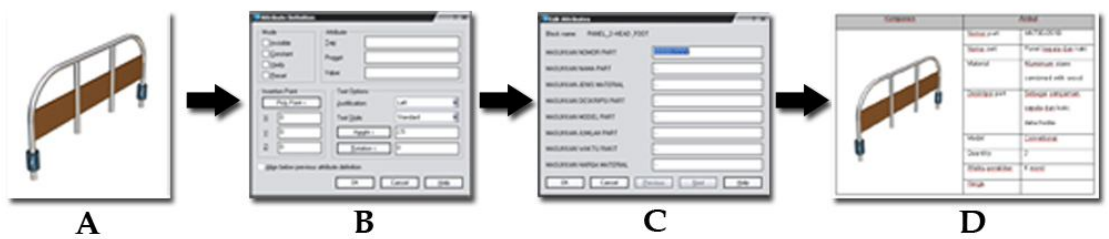

Gambar 2. Pendefinisian atribut pada gambar; (a) komponen yang telah terdefinisi dalam Layer aktif; (b) penentuan atribut-atribut yang akan diekstrak; (c) hasil penentuan atribut dalam bentuk A ttribute Dialog box dan siap diisikan ke objek; dan (d) gambar telah terdefinisi sesuai dengan data yang diisikan.

\subsubsection{Tahap Pengisian Data Atribut}

Setelah masuk ke perintah Insert dan memilih komponen, maka komponen siap dimasukkan ke dalam file gambar aktif. Adapun sistem yang dibangun untuk pemasukan identitas atribut ditunjukkan pada Gambar 3.

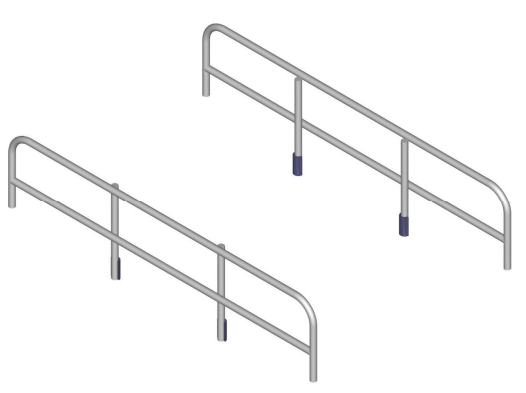

(a)

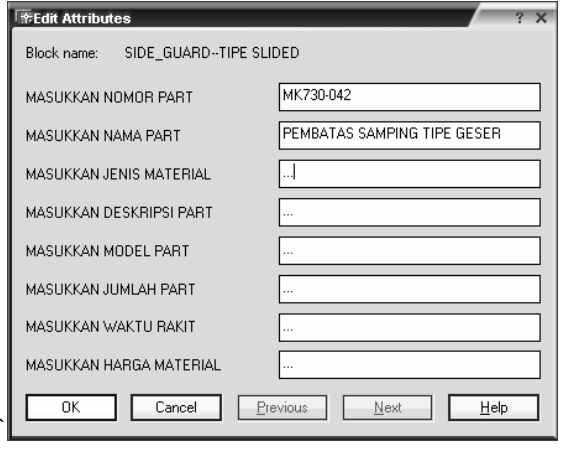

(b)

Gambar 3. Contoh sesi pemberian atribut pada salah satu komponen; (a) gambar; dan (b) fasilitas pemasukan atribut

Pemasukan atribute dari masing-masing part, seperti yang ditunjukkan pada Gambar 3 adalah sebagai basis data penyusunan BOM (bill of material).

\subsubsection{Hasil Ekstraksi A tribut dari Sistem yang Dikembangkan}

Untuk memperoleh data penyusun produk, maka yang perlu dilakukan adalah mengelompokkan seluruh komponen penyusun produk ke dalam satu file. Fungsi dari pengelompokan ini adalah menyatukan entitas-entitas hasil block sehingga membentuk satu produk utuh baik secara gambar maupun data. Di bawah ini merupakan hasil ekstraksi atribut data non-geometris BOM dari AutoCAD ke Microsoft Excel (lihat Tabel 6). 
Tabel 6. Bill of material produk hasil ekstraksi

\begin{tabular}{|c|c|c|}
\hline Block name & Part number & Part_name \\
\hline ALAS-BAGIAN ATAS & MK730-021A & A las bagian atas \\
\hline ALAS--BAGIAN TENGAH 1 & MK730-021B & Alas bagian tengah atas \\
\hline ALAS-BAGIAN TENGAH 2 & MK730-021C & Alas bagian tengah 2 \\
\hline ALAS--BAGIAN BAWAH & MK730-021D & Alas bagian bawah \\
\hline ALAS-HOLDER PANJANG & MK730-022A & Penjepit matras panjang \\
\hline ALAS--HOLDER PENDEK & MK730-022B & Penjepit matras pendek \\
\hline $\begin{array}{l}\text { ALAS--PENGUNCI } \\
\text { PANJANG }\end{array}$ & MK730-023A & Pengunci alas panjang \\
\hline ALAS--PENGUNCI PENDEK & MK730-023B & Pengunci alas pendek \\
\hline INFUSE_STAND & M-36101 & Tiang infuse \\
\hline KAKI--BAGIAN ATAS & MK730-031 & Kaki bagian atas \\
\hline KAKI--BAGIAN TENGAH & MK730-032 & Kaki bagian tengah (penghubung) \\
\hline KAKI--BAGIAN BAWAH & MK730-033 & Kaki bagian bawah \\
\hline KAKI-CASTOR & MK730-035 & Castor (roda) \\
\hline KAKI--PIN JOIN & MK730-036 & Pin join \\
\hline KAKI--TUTUP CASTOR & MK730-035 & Cover castor \\
\hline PANEL_1--DUDUKAN & MK730-052 & Dudukan panel tipe 1 \\
\hline PANEL_1-HEAD \& FOOT & MK730-051 & Panel kepala dan kaki tipe 1 \\
\hline RAN GKA--BEARING BESAR & MK730-013A & Bearing besar \\
\hline RAN GKA--BEARIN G KECIL & MK730-013B & Bearing kecil \\
\hline $\begin{array}{l}\text { RANGKA--HUBREDUCER } \\
\text { PANJANG }\end{array}$ & MK730-012B & Penghubung reducer panjang \\
\hline $\begin{array}{l}\text { RANGKA--HUB REDUCER } \\
\text { PENDEK }\end{array}$ & MK730-012B & Penghubung reducer pendek \\
\hline $\begin{array}{l}\text { RANGKA--POROS } \\
\text { PENGGERAK KECIL }\end{array}$ & MK730-011B & Poros pengangkat kecil \\
\hline RANGKA--POROSUTAMA & MK730-011A & Poros penggerak utama \\
\hline RANGKA--UTAMA & MK730-010 & Rangka utama \\
\hline SIDE_GUARD--TIPE FOLDED & MK730-041 & Pembatas samping bertipelipat \\
\hline $\begin{array}{l}\text { SISTEM_PENGGERAK--DC } \\
\text { MOTOR }\end{array}$ & MK730-311 & Motor arus searah \\
\hline $\begin{array}{l}\text { SISTEM_PENGGERAK- } \\
\text { HIDROLIK }\end{array}$ & MK730-312 & Hydrolic pump \\
\hline $\begin{array}{l}\text { SISTEM_PENGGERAK- } \\
\text { REDUCER }\end{array}$ & MK730-313 & Reducer 1:30 \\
\hline $\begin{array}{l}\text { SISTEM_PENGGERAK- } \\
\text { TRANSPORTER }\end{array}$ & MK730-314 & Transporter \\
\hline MATRAS & MK730-315 & Matras \\
\hline
\end{tabular}




\subsubsection{Ilustrasi Proses Perancangan}

Untuk lebih memudahkan memahami konsep pengembangan perancangan dan perencanaan produksi, Gambar 4 memberikan ilustrasi proses dimulai mendapatkan preferensi konsumen, pengambilan data antrophometri, pendesainan hingga animasi proses perakitan

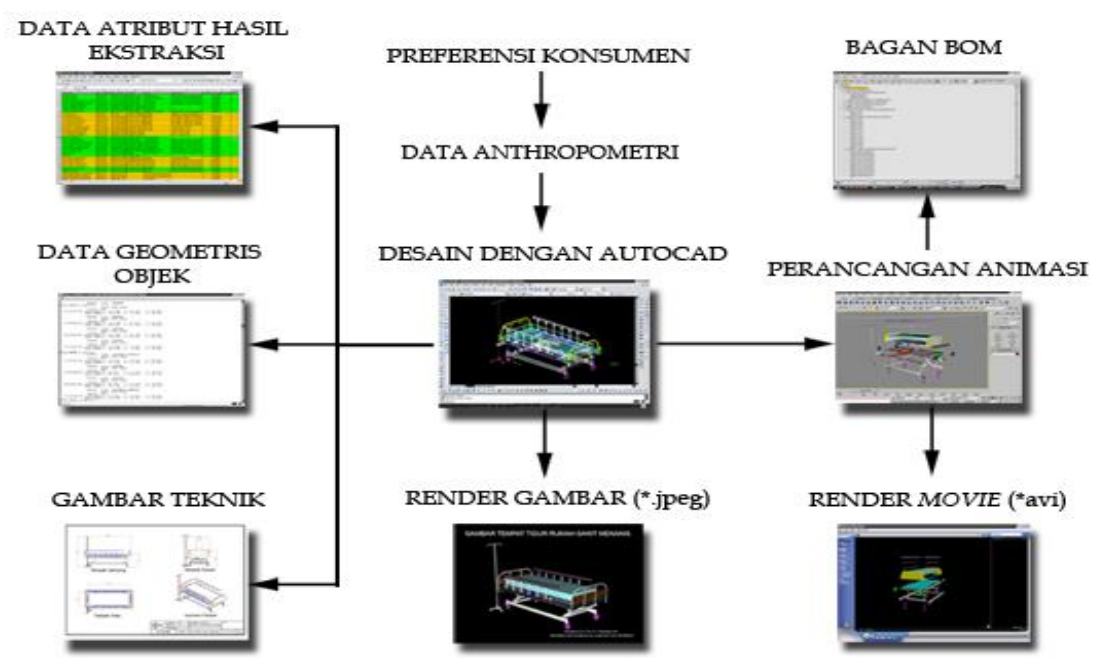

Gambar 4. Ilustrasi proses perancangan

\section{PEMBAHASAN}

\subsection{Proses Desain dengan AutoCAD}

Proses pembuatan gambar menggunakan teknik konversi struktur bangun 2D $\rightarrow$ 3D. Desain 2D yang telah dikonversi strukturnya dilakukan secara terpisah untuk masing-masing komponen penyusun produk disesuaikan dengan BOMnya. Desain pada tahap ini memanfaatkan entity dasar dan perintah editing 2D serta editing 3D.

\subsection{Penambahan Atribut Data Gambar}

Penambahan atribut pada gambar komponen produk yang diteliti berfungsi untuk memberikan informasi-informasi mengenai komponen yang dibutuhkan kepada bagian produksi dan konsumen. Informasi-informasi yang diperlukan antara lain nomor part, nama part, material, model, deskripsi part, jumlah part, waktu perakitan tiap komponen, dan harga tiap komponen. Data untuk masingmasing komponen dibuat dengan mendefinisikan Attribute terlebih dahulu dan kemudian menyatukan seluruh A ttribute yang dibuat ke dalam satu Block dengan mendefinisikannya pada metode WBlock. Perintah ATTDEF akan memberikan pilihan untuk mendefinisikan Attribute mulai dari titik penempatannya, tinggi huruf, tag hingga mode yang diinginkan. 


\subsection{Penggabungan Komponen M enjadi Produk Utuh}

Dalam menggabungkan komponen-komponen produk untuk membuat satu produk jadi, penulis menggunakan perintah insert block. Perintah ini digunakan untuk:

1. Meletakkan objek baru yang akan dimasukkan ke dalam file gambar pengel ola data

2. Sebagai pengaktif data dari sistem yang dibangun

3. Sebagai penentu apakah objek yang akan dimasukkan tersebut berupa entitas solid atau entitas dalam bentuk block

Keuntungan dari menggunakan perintah ini adalah waktu loading tidak terlalu lama untuk kebutuhan sistem standar dan data yang ditampilkan akan lebih lengkap, baik data yang bersifat geometris objek maupun non-geometris (atributivitas). Gambar 5 adalah contoh hasil desain tempat tidur pasien rumah sakit.

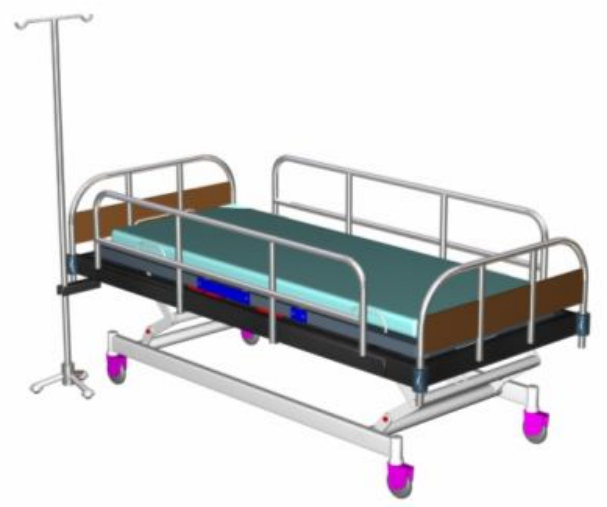

Gambar 5. Salah satu contoh hasil desain tempat tidur pasien rumah sakit

\subsection{Ekstraksi A tribut Penyusun Produk (Bill of M aterials Extractor)}

Untuk memperoleh data penyusun produk, maka yang perlu dilakukan adalah mengelompokkan seluruh komponen penyusun produk ke dalam satu file. Fungsi dari pengelompokan ini adalah menyatukan entitas-entitas hasil block sehingga membentuk satu produk utuh baik secara gambar maupun penyediaan basis data.

\section{SIMPULAN DAN SARAN}

\subsection{Simpulan}

Beberapa simpulan yang dapat ditarik adalah:

1 Pemanfaatan prosedur perancangan Layer Properties, Insert Block serta metode WBlock dan Attribute Extraction pada CAD telah mampu menghasilkam rancangan desain menjadi ergonomic dan lebih estetis.

2. Bill of $M$ aterials produk dapat diperoleh secara otomatis dengan memanfaatkan metode A ttribute Extraction pada CAD. 


\subsection{Saran}

Dengan penggunaan metode Attribute Extraction dalam perilaku perancangan produk tempat tidur pasien, maka hasil keluaran yang dapat diperoleh menjadi lebih lengkap sehingga dalam penelitian selanjutnya dapat diteruskan ke proses permesinan (CAM) dan analisis kekuatan material (CAE).

\section{PUSTAKA}

[1] Autodesk (2005) A utoCA D 2005 U ser's Guide, Autodesk Canada Inc., Canada.

[2] Bedworth, D.D., et al. (1991) Computer Integrated Design and M anufacturing, Mc.Graw Hill International Editions, Singapore.

[3] Chang, T., dan Wysk, R.A. (1998) Computer-Aided M anufacturing (Second Edition), Prentice Hall International Inc, New Jersey.

[4] Jones, C.J., dan Ertas, A. (1996) The Engineering Design Process, Texas Tech University, John Wiley \& Sons Inc., Texas.

[5] Middleditch, A.E., Reade, C.M.P. (2000) Theories of Shape and Cell Structure for Computer Aided Design, Workshop on Geometric Modeling and Computer Graphics, Seoul.

[6] Prasetyowibowo, B. (2002) M anajemen Desain,, Yayasan Delapan-Sepuluh, Bandung.

[7] Rahayu, T.S. (2001) Perancangan Ulang Tempat Tidur Dengan Menggunakan Metode Value Engineering Dan Data Antropometri, Tugas A khir, Jurusan Teknik Industri Fakultas Teknologi Industri Universitas Islam Indonesia, Yogyakarta.

[8] Rao, P.N. (2002) CAD/CAM Principles and Applications, University of Iowa, McGraw Hill Inc., lowa.

[9] Wahyono, A.D. (2001) Pemanfaatan Computer-Aided Design Pada Perancangan Produk Yang Berorientasi Pada Konsumen, Tugas A khir, Jurusan Teknik Industri Fakultas Teknologi Industri Universitas Islam Indonesia, Yogyakarta.

[10]Wignjosoebroto, S. (1995) Ergonomi, Study Gerak dan Waktu PT. Guna Widya, Surabaya. 